\title{
International and internal migration measured from the School Census in England
}

Ludi Simpson, Naomi Marquis, Stephen Jivraj

University of Manchester

\section{Summary}

The School Census is the only regularly updated dataset covering almost all of the population of a specific age, which records changes of address along with ethnicity and some family economic circumstances. It can be used to measure internal and international family migration as shown in this report.

The School Census is suited to identify and quantify new local migration streams between censuses, successfully identifying the local distribution of Eastern European immigration in the decade since 2000 .

The measures do not provide a complete measure of migration, either internally or internationally. The exclusion of those outside the state school system means that internal migration is under-estimated, and international migration is approximately measured.

The advantages of the School Census are its frequent updates, its fine geographical information, and its indicators of ethnicity and low family income, which powerfully complement other sources. 


\section{Contents}

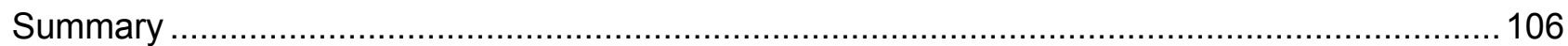

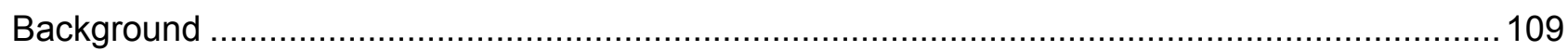

Aims

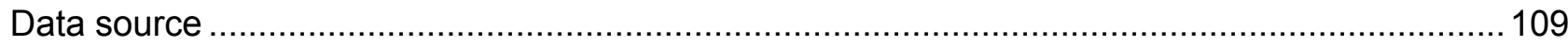

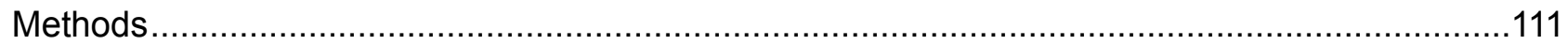

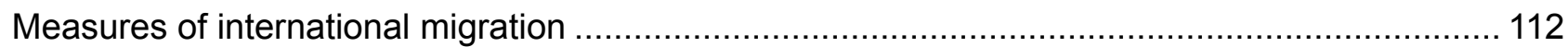

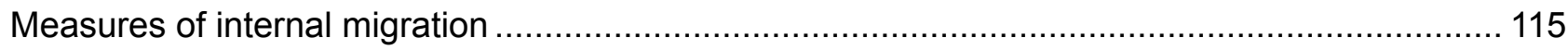

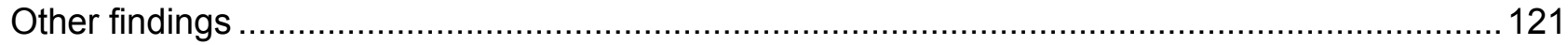

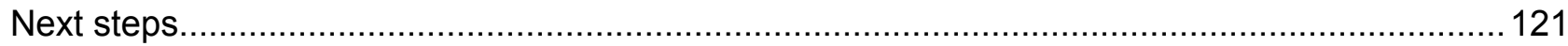

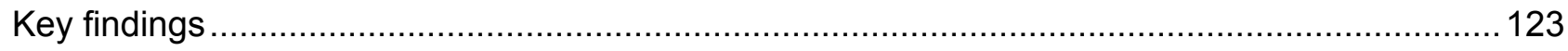

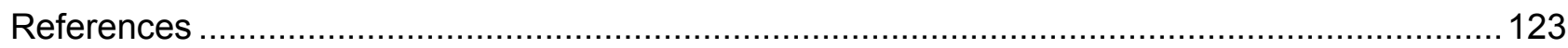

\section{List of figures}

Figure $1 \quad$ National Insurance Number Allocations from A8 countries (2003-2006) compared to late-starting pupils with language other than English 2003-2007 ...

Figure 2 Migration within England from School Census and patient registration data compared for local authority areas, 2002/03 to 2006/07 .................................... 117

Figure 3 Age at internal move, School Census and Population Census compared .............. 119

Figure $4 \quad$ Ethnicity of pupils moving internally, School Census and Population Census compared

Map 1 Percentage of immigrant pupils arriving between January 2002 and January 2007 as recorded in English School Census by local authority...................................... 122 


\section{List of tables}

Table 1 Missing, invalid or inconsistent content of the School Census, January 2007 111

Table 2 Quality of postcode field

Table 3 Immigrants to England of school age from the 2001 Census, compared to late starters in the School Census aged $6-15$, with $\%$ of all children or pupils

Table $4 \quad$ Pupils and immigrants during 2002/3 to 2006/7

Table 5 Moves between districts: School Census and patient registrations compared (ages 5-15), 2002-03 to 2006-07

Table 6 Moves within England, School Census and Population Census compared (ages 5-15) 


\section{Background}

The combined expansion of publicly funded administrative databases, relatively inexpensive computing power, and competition for local resources based on evidence of need, has led to expectations of more local data with ethnicity and economic detail ${ }^{1,2}$. Administrative databases such as the School Census for state school pupils in England have the potential to provide relevant information, albeit for an incomplete subset of the population.

Migration statistics, both within the country and overseas, are the weakest part of national demographic monitoring systems in the UK as elsewhere ${ }^{3,4}$. If the School Census can be used to identify immigrant pupils and residential moves within England, then it potentially helps to answer specific questions arising from social policy concerns between the decennial censuses. For how long do international migrants tend to have unsettled residence in the UK? Do poor families move more frequently than others, but less far? Is immigration concentrated in the same areas as in the past, and has dispersal from concentrations continued since 2001? Do those who best prosper in poor areas tend to move out? Which area-based regeneration schemes might keep advantaged residents in order to make a lasting difference?

The School Census cannot measure all migration. It does not cover the whole population of school age, does not identify children who immigrated before school age, and the level of migration at school age is less than for younger children. Child migration differs from adult migration since there are different numbers of children in each household. But the School Census potentially gives good local indicators of the stock of families and of family migration, with additional indicators of ethnicity, language and welfare claimant status, and is sensitive to short-term changes. It includes children who move without family, for example to or between foster parents or separated parents.

In the past, administrative records have been used to measure population and migration with an ethnic dimension for specific local areas using name analysis of the electoral register ${ }^{5}$, health records $s^{6}$, and using ethnicity recorded on pupil records ${ }^{7}$. This article focuses on migration and is the first to use the School Census to create indicators of international and national migration for each local authority of England ${ }^{8}$.

\section{Aims}

This article attempts to demonstrate the value of the School Census of England for measuring migration. To some extent we do not expect new results, because we validate the School Census against the less detailed indicators of migration available from the 2001 Census, health patient registers, and the National Insurance Registration system. The unique insights from the School Census that do arise from its local, annually updated, and socially classified nature will be referred to more briefly.

The School Census remains only a useful proxy and will not stop the search for better and more complete measures of migration and its socio-economic characteristics.

\section{Data source}

The School Census (formerly the Pupil Level Annual School Census) is derived from an administrative form completed electronically by each state school in England and submitted to the Department for Children, Schools and Families (DCSF) by each Local Education Authority (LEA). 
Since 2002 the pupil level census has been conducted annually on the third Thursday of January, supplemented since 2006 with further data collection in the summer and autumn school terms. Similar administrative systems have operated in Wales, Scotland and Northern Ireland since 2005 or more recently.

The census includes a record for each pupil who was in the state education system at the time of data collection, for whom the census is statutory. While the proportion of school age children not in state schools is about 8 per cent for England as a whole, it varies between LEAs ${ }^{9}$.

The census content from each school is validated locally and by the DCSF, compiled into a national dataset and integrated within the National Pupil Dataset (NPD) which also contains attainment and other data for each pupil and school. The data are linked through unique pupil and establishment numbers.

The data utilised in this article are for the January census in each year from 2002 to 2007, covering the academic years 2001-02 through to 2006-07, and were supplied by the DCSF to the University of Manchester in 2007 as individual files for each census. Box one shows the attributes included in the School Census.

\section{Box one Pupil attributes in the School Census}

$\begin{array}{ll}\begin{array}{l}\text { Age } \\ \text { Entry }\end{array} & \text { Age at the start of the school year } \\ \text { Establishment } & \text { Date starting at current establishment } \\ \text { Ethnic Group* } & \text { Detailed ethnicity with } 96 \text { categories, from 2002/03 } \\ \text { Language indicator } & \text { Whether pupil's first language is believed or known to be En } \\ \text { Schools are instructed to record a language other than English when more than on } \\ \text { is spoken at home, irrespective of the child's proficiency in English. } \\ \begin{array}{ll}\text { Language* } & \text { Name of first language if other than English, from 2006/07 } \\ \text { FSM } & \text { Whether a child is in receipt of Free School Meals } \\ \text { Gender } & \text { Male or Female }\end{array}\end{array}$

Name*

Date of Birth*

Address $^{*}$, postcode* ${ }^{*} \quad$ Address, postcode and census area of residence

* These fields are designated as sensitive and may not be released. Less detailed versions may nonetheless be available: Census 2001 categories of ethnicity rather than full detail, census area or postal district of residence rather than postcode, month of birth rather than date of birth. The extract used for this article accessed postcode and detailed ethnicity, but not name, address, date of birth or name of first language.

Other fields in the School Census, but not accessed for this study, identify children of Service personnel, with Special Educational Needs, in care, exclusions, boarders and those in the Gifted and Talented scheme. 


\section{Methods}

\section{Creating a longitudinal dataset}

The file for each year includes between seven and eight million pupil records. The Pupil Matching Reference allows records for the same pupil to be linked across years to create a longitudinal dataset from which migration may be measured. Matching records across years is not possible if the reference is missing, which led to the exclusion of 613 records for pupils of compulsory school age 5-15 at the start of the school year (less than 0.01 per cent), or if the reference is not unique, which led to the exclusion of a further 943 records (less than 0.02 per cent of the total in any of the years). Excluded records may bias results, but the number involved does not give reason to be concerned, especially as there was no clear geographical pattern among those excluded.

\section{Dealing with missing, invalid and inconsistent data}

Some relevant information was missing, or contained an invalid entry, or was inconsistent across the years for which the pupil was present in the database. 'Errors' of these three types were reduced by using the same pupil's data for years which are neither missing nor invalid.

For month and year of age and of birth, for gender, and for the indicator of first language, three rules were used to establish the most likely value: (a) valid values were favoured over invalid or missing values; (b) if more than one valid value was present in different years, the most often occurring value was favoured; (c) if more than one valid value was present for an equal number of years, the most recent was favoured, as possibly reflecting a correction of previous errors.

As summarised for the year 2007 in Table 1, less than one per cent of pupils required changes to these variables, and 85 per cent or more of such records could be improved by interpolating a single valid value using these three rules. The remaining records contained missing or invalid values for every year, and could not be improved. Across all six years a total of 23,505 matched pupils remained with missing age information; 21,441 (91.2 per cent) of these were present in the dataset for just one year.

Eligibility for Free School Meals can legitimately change from one year to another as family circumstances change, and was not amended.

\section{Table 1 Missing, invalid or inconsistent content of the School} Census, January 2007

\begin{tabular}{lrrrrrrr}
\hline & Ethnicity & $\begin{array}{r}\text { First } \\
\text { Language } \\
\text { (whether } \\
\text { English) }\end{array}$ & $\begin{array}{r}\text { Free School } \\
\text { Meals } \\
\text { Eligibility }\end{array}$ & $\begin{array}{r}\text { Gender } \\
\text { Ange in Years } \\
\text { at start of } \\
\text { academic year }\end{array}$ & $\begin{array}{r}\text { Month of } \\
\text { Birth }\end{array}$ & $\begin{array}{r}\text { Year of } \\
\text { Birth }\end{array}$ \\
\hline Total records & $7,303,423$ & $7,303,423$ & $7,303,423$ & $7,303,423$ & $7,303,423$ & $7,303,423$ & $7,303,423$ \\
With field entry & $7,140,547$ & $7,201,555$ & $7,256,317$ & $7,303,423$ & $7,303,419$ & $7,303,423$ & $7,303,423$ \\
With error* & $1,127,312$ & 676,942 & 47,106 & 35,807 & 20,053 & 46,146 & 22,067 \\
With entry after interpolation & $7,215,908$ & $7,257,686$ & $7,256,317$ & $7,267,616$ & $7,300,493$ & $7,257,277$ & $7,302,206$ \\
Missing after interpolation & 87,515 & 45,737 & 47,106 & 35,807 & 2,930 & 46,146 & 1,217 \\
\% errors fixed & $92.2 \%$ & $93.2 \%$ & $0 \%$ & $0 \%$ & $85.4 \%$ & $0 \%$ & $94.5 \%$ \\
\% records valid after cleaning & $98.8 \%$ & $99.4 \%$ & $99.4 \%$ & $99.5 \%$ & $100 \%$ & $99.5 \%$ & $100 \%$ \\
\hline
\end{tabular}

* Error: any record with an invalid or missing entry for the field shown in the column heading. Interpolation is the use of records for other years to correct or complete or make consistent the field for this year, as described in the text. 
'Ethnicity' is recorded in the School Census allowing entry of one of 96 categories which have been in use since 2003. A second variable, labelled 'ethnic group', contains the sixteen categories used in the 2001 Census, and since 2003 has been derived by the DCSF from the extended categories, for example allocating 'White Eastern European' to the broader Census category of 'Other White'. Table 1 shows that these two ethnicity categories and the indicator of whether the pupil's first language is other than English, were more liable to change over time than age and gender when recorded in the School Census.

Ethnicity and language are not usually updated annually by each school, but more usually when the pupil changes school, particularly between infant and junior, or primary and secondary stages of schooling. A change may record a real change in parent or pupil's claimed identity but in the majority of cases are found to be a change between no recorded ethnicity and a recorded ethnicity. For 2007, a consistent ethnicity could be derived for all but 88,000 pupils (1.2 per cent) by the three rules described above, with the additional proviso that in an inconsistency between less detailed and more detailed categories (African and Nigerian, for example), the more detailed category was favoured.

\section{Validating postcodes}

Pupil home postcodes recorded in the School Census were checked against the Office for National Statistics' National Statistics Postcode Directory and its predecessors. Table 2 shows that since 2003 more than 98 per cent of records have a valid postcode.

\section{Table 2 Quality of postcode field}

\begin{tabular}{lrrrr}
\hline & $\begin{array}{r}\text { Valid } \\
\text { Postcode } \\
\text { per cent }\end{array}$ & $\begin{array}{r}\text { Missing } \\
\text { Postcode } \\
\text { per cent }\end{array}$ & $\begin{array}{r}\text { Invalid } \\
\text { Postcode } \\
\text { per cent }\end{array}$ & $\begin{array}{r}\text { Total } \\
\text { Records }\end{array}$ \\
\hline 2002 & 96.9 & 1.2 & 1.9 & $7,745,581$ \\
2003 & 98.3 & 0.2 & 1.5 & $7,739,246$ \\
2004 & 98.5 & 0.2 & 1.3 & $7,733,277$ \\
2005 & 98.1 & 0.1 & 0.8 & $7,143,366$ \\
2006 & 98.8 & 0.0 & 1.2 & $7,316,112$ \\
2007 & 98.3 & 0.7 & 1.0 & $7,303,423$ \\
\hline
\end{tabular}

\section{Measures of international migration}

Box two shows the chosen measures of international migration, emphasising the approximate nature of the indicators. The measure provides sub-national detail, each year, which can be related to an indicator of economic circumstances while in school (Free School Meals) and world origin measured by ethnicity and language. While the number of immigrant pupils arriving in any year may be well estimated, the total number of international migrants among pupils is under-estimated, because the measures exclude immigration before school age and migration outside the period studied.

\section{Comparison with other measures of international migration}

The first year of the School Census, closest in timing to the 2001 Census of Population, indicates that 0.59 per cent of school-aged children without English as their home language had immigrated 


\section{Box two Measures of international migration}

The School Census currently has no direct indicator of a pupil's residence outside England, nor country of birth. The following are indicators of potential international migration, using the pupil's age at the start of the school year in which he or she is first identified in the School Census.

- Entry to school after age 5 indicates possible immigration.

- Entry to school after age $\mathbf{5}$ where additionally English is not the first language identifies pupils who are most likely to be immigrants.

- Leaving school before age 15 indicates possible emigration.

- Leaving school before age $\mathbf{1 5}$ where additionally English is not the first language identifies pupils who are most likely to be emigrants.

These measures of those most likely to be international migrants include some non-immigrants, for example pupils moving from Scotland, Wales or Northern Ireland, and those spending some time outside state schools before joining state schools in England. The condition of a first language other than English reduces the number of these false inclusions. The measures exclude immigrant pupils into non-state schools, immigrants whose first language is English (a substantial population: ONS unpublished statistics show USA and South Africa among the top five countries in 2008 among the birthplaces of foreign-born children aged 0-15), pupils who immigrated before school age, or before the School Census was collected.

\section{Table 3 Immigrants to England of school age from the 2001 Census, compared to late starters in the School Census aged 6-15, with $\%$ of all children or pupils}

\begin{tabular}{lcc}
\hline Population Census: year to April 2001 & 30,512 & $0.48 \%$ \\
\hline School Census: year to Jan 2003 & 33,865 & $0.59 \%$ \\
\hline
\end{tabular}

in one year, compared to 0.48 per cent of all school-age pupils recorded in the Census. This suggests that the School Census either over estimates immigration of school pupils or that immigration of non-English speaking children rose between 2000-01 and 2002-03.

The origin of pupils who have probably immigrated is not recorded directly but is indicated by their ethnicity. There is evidence that ethnicity is recorded differently in each LEA. For example White English is used for 88 per cent of pupils in Kent, but for less than 10 per cent of pupils in neighbouring Surrey where White British is most often used. This is presumably a preference of the educational administrators rather than of pupils or parents.

Variation in the use of other ethnicity categories affects the measurement of immigration. Eastern European origins may be recorded as 'White Eastern European', 'White European', 'Any Other White Background' and 'Other White', as well as other less likely but valid entries, for example those without a White description. 
Figure 1 National Insurance Number Allocations from A8 countries (2003-2006) compared to late-starting pupils with language other than English 2003-2007

(a) White Eastern European pupil ethnicity

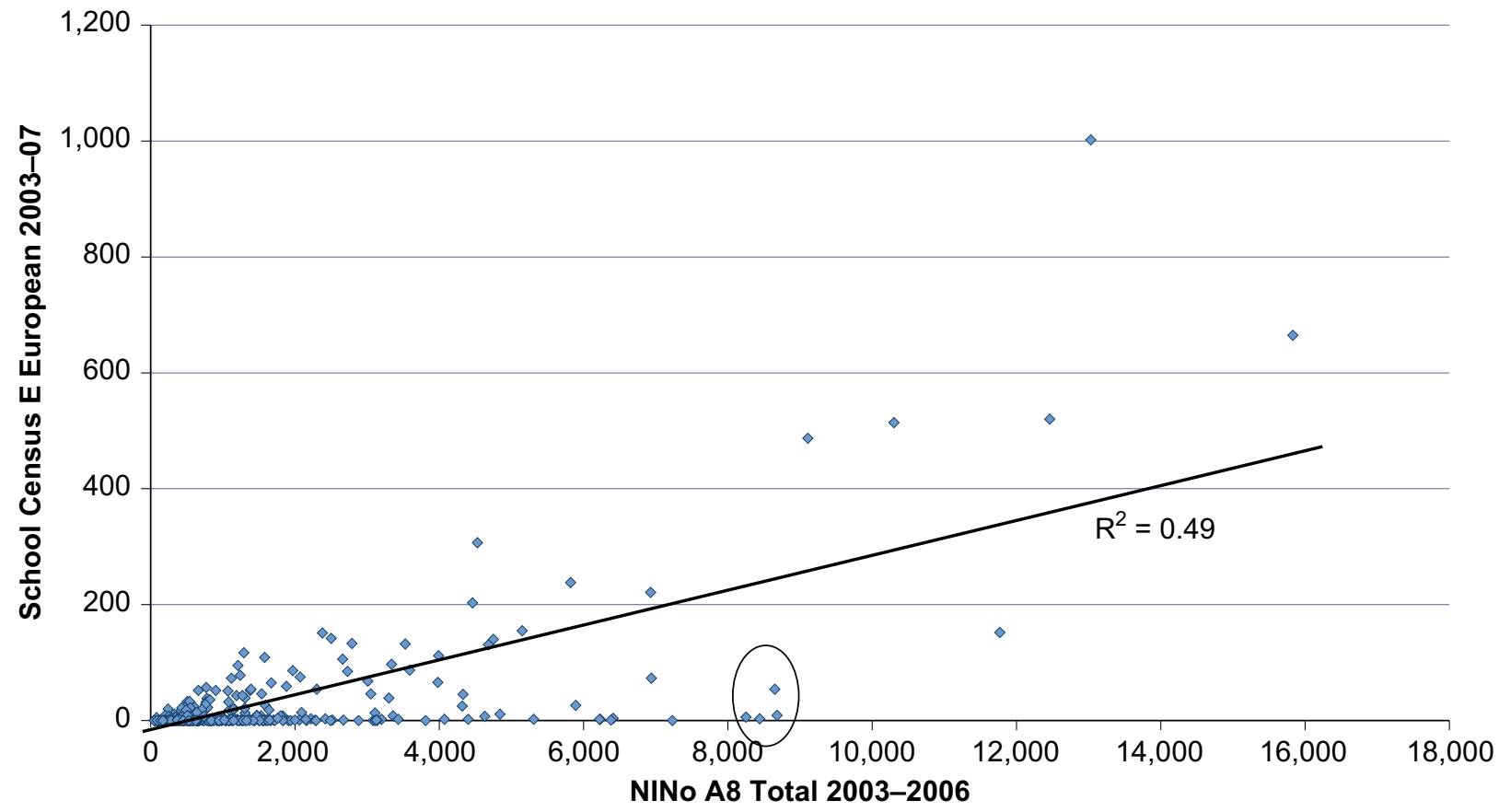

Note: Manchester, Peterborough, Luton and Birmingham are ringed (see text)

(b) Potential Eastern European pupil ethnicity (4 categories, see text)

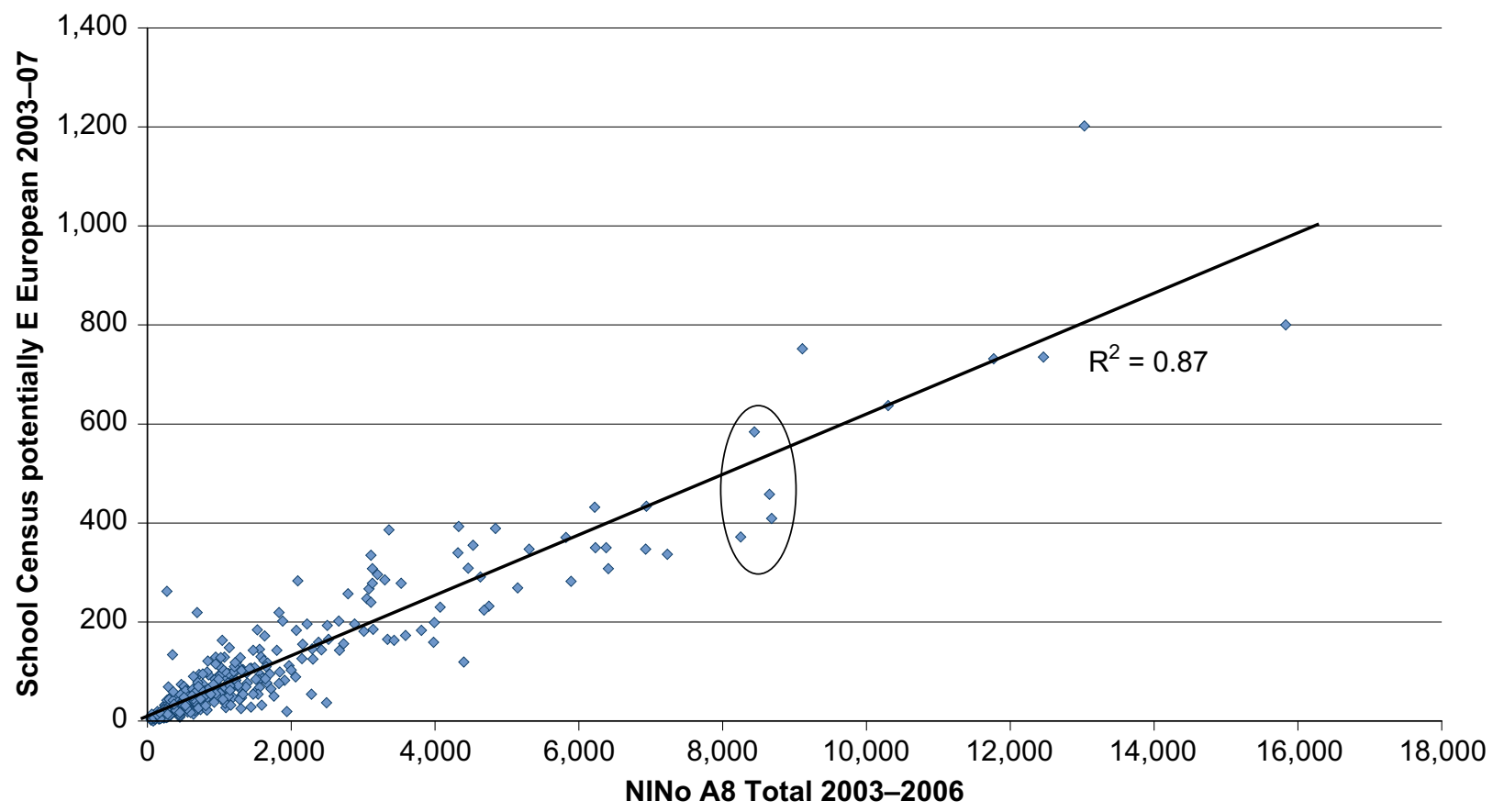

Note: Manchester, Peterborough, Luton and Birmingham are ringed (see text)

Figure 1 compares for each local authority district in England the number of pupils most likely to be immigrants (late starters with first language other than English) with the number of new allocations of National Insurance numbers in the same period from the Eastern European 'A8' countries new to the European Union. 


\section{Table $4 \quad$ Pupils and immigrants during 2002/3 to 2006/7}

\begin{tabular}{|c|c|c|c|c|c|}
\hline \multirow[b]{2}{*}{ Eastern European } & \multirow{2}{*}{$\begin{array}{r}\text { All pupils } \\
20,074\end{array}$} & \multicolumn{2}{|c|}{ Likely to be immigrants } & \multicolumn{2}{|c|}{ Likely to be emigrants } \\
\hline & & 8,678 & $43.2 \%$ & 1,219 & $6.1 \%$ \\
\hline African & 210,959 & 41,288 & $19.6 \%$ & 9,511 & $4.5 \%$ \\
\hline Italian or Portuguese & 8,255 & 1,415 & $17.1 \%$ & 446 & $5.4 \%$ \\
\hline White European & 28,896 & 4,911 & $17.0 \%$ & 1,440 & $5.0 \%$ \\
\hline Chinese & 32,824 & 5,346 & $16.3 \%$ & 2,098 & $6.4 \%$ \\
\hline Other White, not Britain//reland & 156,400 & 22,915 & $14.7 \%$ & 7,160 & $4.6 \%$ \\
\hline Western European & 20,320 & 2,414 & $11.9 \%$ & 1,305 & $6.4 \%$ \\
\hline Gypsy/Roma & 13,722 & 1,428 & $10.4 \%$ & 689 & $5.0 \%$ \\
\hline Ex Yugoslavia/Albania & 6,891 & 610 & $8.9 \%$ & 370 & $5.4 \%$ \\
\hline All Other Origins & 622,533 & 54,948 & $8.8 \%$ & 20,527 & $3.3 \%$ \\
\hline Turkish/Turkish Cypriot & 21,684 & 1,833 & $8.5 \%$ & 926 & $4.3 \%$ \\
\hline Indian & 206,809 & 14,627 & $7.1 \%$ & 7,360 & $3.6 \%$ \\
\hline Bangladeshi & 106,313 & 6,671 & $6.3 \%$ & 4,667 & $4.4 \%$ \\
\hline Pakistani & 266,063 & 16,492 & $6.2 \%$ & 11,337 & $4.3 \%$ \\
\hline Greek/Greek Cypriot & 7,952 & 193 & $2.4 \%$ & 208 & $2.6 \%$ \\
\hline White (Britain/Ireland) & $7,209,976$ & 2,136 & $0.03 \%$ & 1,829 & $0.03 \%$ \\
\hline All ethnicities & $8,939,671$ & 185,905 & $2.10 \%$ & 71,092 & $0.80 \%$ \\
\hline
\end{tabular}

Figure 1a includes pupils who are directly recorded as 'White Eastern European', while Figure $1 \mathrm{~b}$ extends to any of the four categories which are likely to be used to indicate Eastern European origin. There is a strong relationship between the adult immigration indicated by new National Insurance allocations and the pupil immigration indicated by the School Census, but it is clear that some local authorities with sizeable Eastern European immigration did not use the code 'White Eastern European'. Significant Eastern European immigration to Manchester, Peterborough, Luton and Birmingham is only identified from the School Census when the less specific categories of White European, Any Other White Background and Other White are included.

These analyses confirm the robustness of the School Census to indicate the local distribution of international migration and its strong relation with adult immigration. However, care must be taken when interpreting ethnicity as region of origin, and the difference between adult and child migration should not be ignored.

Table 4 shows the number of likely immigrant and emigrant pupils during 2002/03-2006/07 (latestarting and early-leaving pupils with first language other than English) for selected categories of ethnicity, expressed as a percentage of pupils of that ethnicity who were aged 5-15 in school for at least one of those years. The categories are sorted in decreasing order of the percentage of pupils who immigrated during the period, which ranges from over 43 per cent for those recorded with Eastern European ethnicity, to less than 0.1 per cent for those recorded with English, Welsh, Scottish, Irish or British White ethnicity.

\section{Measures of internal migration}

Box three shows the chosen measures of internal migration within England, based on a change of postcode between adjacent years. This is the same approach taken currently to measure migration 


\section{Box three Measures of internal migration}

A pupil year is counted whenever the pupil has a valid postcode in both of two adjacent years.

A change of postcode in a pupil year indicates a move within England during that year.

Two sets of conditions exclude changes of postcode that are unlikely to represent residential moves:

\section{Excluded because the postcode change is probably the correction of a clerical error:}

(a) where there is a change in the length of a postcode by one character, with all other characters remaining unchanged; (b) where the first or last two characters are coded in reverse compared with the previous postcode; (c) where either of the first or last two characters only change; (d) where the first and last two characters all remain unchanged;

\section{Excluded because the postcode change is probably the result of Royal Mail}

administration: (e) where the Euclidean (straight line) distance between the centroids of the two postcodes was less than 100 metres; (f) where more than eight pupils move between the same two postcodes; and $(\mathrm{g})$ where more than eight pupils move out of a postcode which is not used in the consecutive year.

The result of these conditions was exclusion of approximately 6 per cent of the pupils who would otherwise have been considered internal migrants. The greatest exclusion was of apparent short distance moves within electoral wards. A test replacement of (e) to (g) by direct lists of changed Royal Mail postcodes reduced the exclusions to 1 per cent, accepting many more of the short distance moves. Further work may find that the validation of postcodes using the National Statistics Postcode Directories is sufficient without further exclusions.

The number of moves as a proportion of pupil years uses an appropriate denominator to indicate the rate of migration.

Distance of move, administrative boundaries crossed, characteristics of pupils who move, and multiple moves during several annual periods can all be additionally identified.

without an ethnic group dimension, from successive annual extracts from the NHS health authority patient registers ${ }^{10}$. The concept of pupil year is important, to distinguish the number of years that each pupil is present in the dataset 'at risk' of migrating. It allows a fair comparison of groups who are present in the dataset for varying lengths of time. This is important when comparing the internal migration of all people with that of immigrant pupils, who by their nature have arrived in school at a later age and therefore have fewer pupil years in the period studied.

\section{Comparison with other measures of migration within England}

In the UK, health authority patient registrations are used for government estimates of migration between local authority districts. Figure 2 shows a close relationship between these estimates for children aged 5-15 and those from the School Census, for moves between the 354 districts of England. Table 5 shows that the total number of moves between districts is about 20 per cent lower on the School Census than on patient registrations. This may be partly because moves by 
Figure 2 Migration within England from School Census and patient registration data compared for local authority areas, 2002/03 to $2006 / 07$

Inflows English LAs

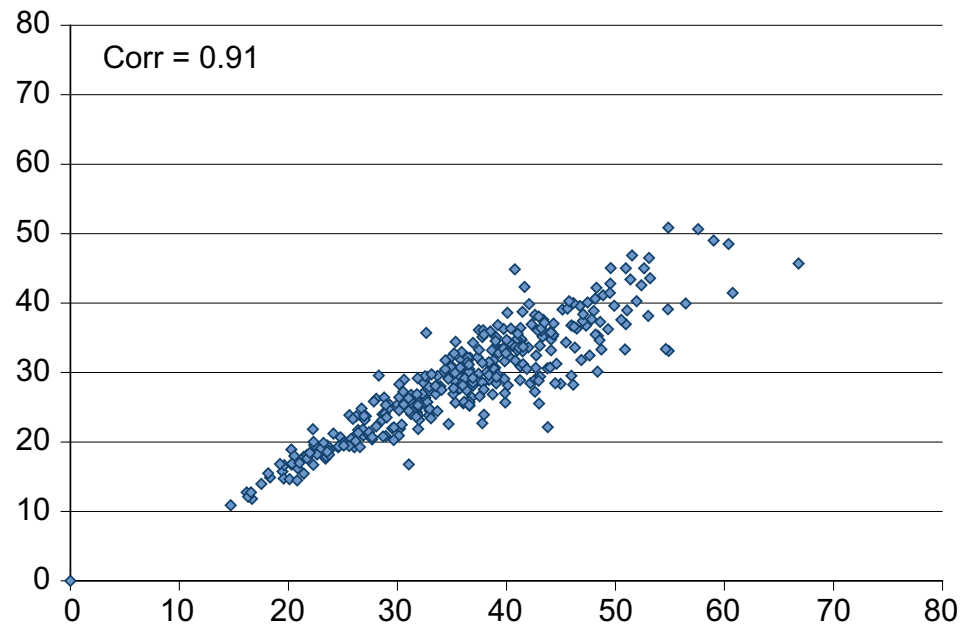

Outflows English LAs

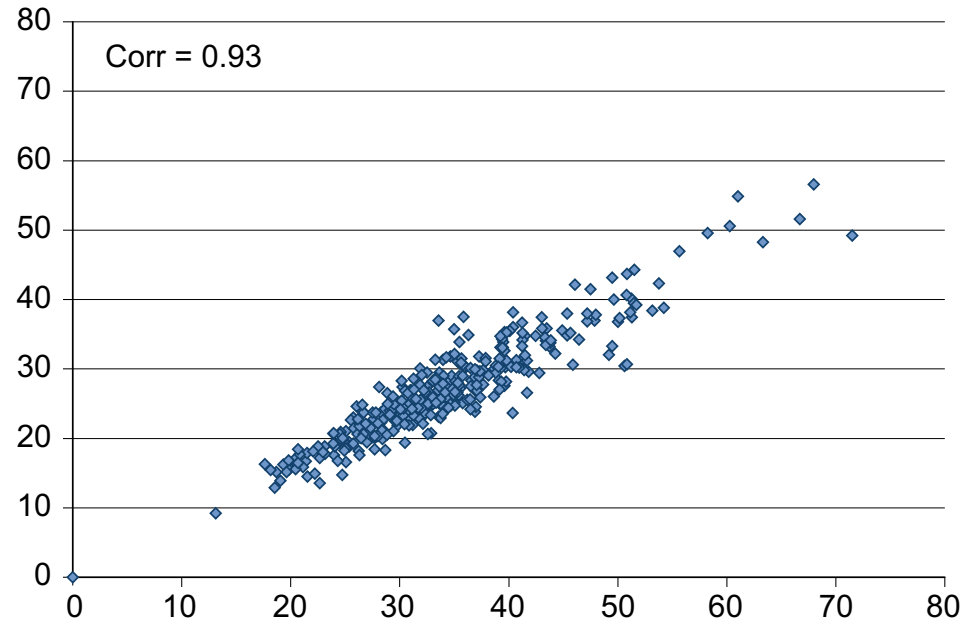

Net flows, English LAs

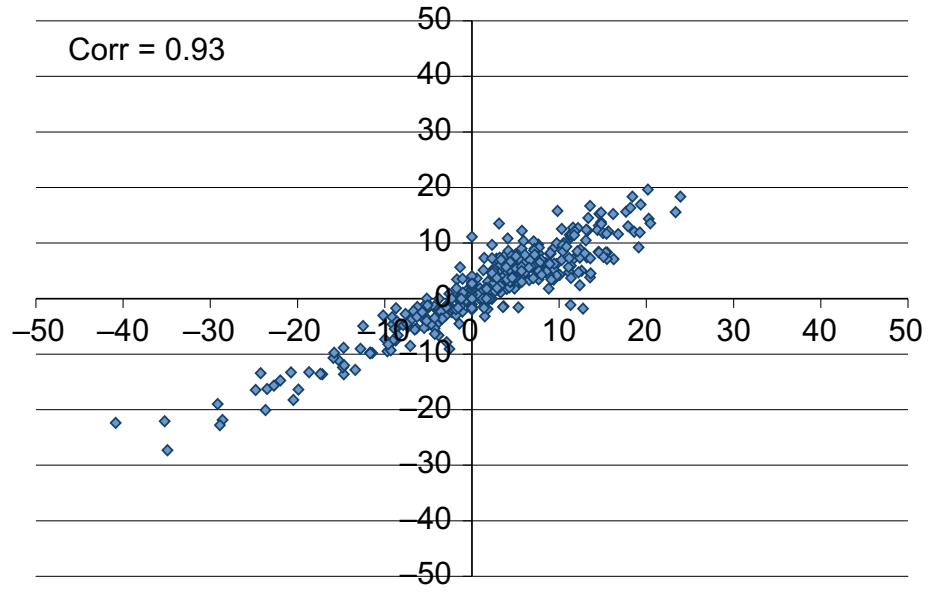

Vertical axes: School Census, rate per 1,000 aged 5-15 years.

Horizontal axes: Patient registration, rate per 1,000 aged 5-15 years 
Table 5 Moves between districts: School Census and patient registrations compared (ages 5-15), 2002-03 to 2006-07

\begin{tabular}{lcccc}
\hline Period & $\begin{array}{c}\text { School } \\
\text { Census }\end{array}$ & $\begin{array}{c}\text { Patient } \\
\text { registrations }\end{array}$ & Difference & Ratio \\
\hline $2002-03$ & 179,498 & 236,240 & $-56,742$ & 0.760 \\
$2003-04$ & 173,464 & 233,390 & $-59,926$ & 0.744 \\
$2004-05$ & 173,189 & 214,800 & $-41,611$ & 0.807 \\
$2005-06$ & 145,605 & 212,100 & $-66,495$ & 0.687 \\
$2006-07$ & 166,143 & 218,120 & $-51,977$ & 0.762 \\
\hline
\end{tabular}

those outside the state school system are omitted, and partly because the patient re-registrations are adjusted to estimate all moves including by children who may move more than once during a year.

The School Census records about the same number of child moves as the Population Census between districts, but more moves within districts (Table 6). Both sources measure changes of address over the period of one year, and the Census is known to undercount moves. However, although referring to a different year and the coverage is not the same in each data source, it is not clear why the proportion of moves within districts should be so much lower in the Population Census ${ }^{11}$.

\section{Table $6 \quad$ Moves within England, School Census and Population Census compared (ages 5-15)}

\begin{tabular}{lccccr}
\hline & \multicolumn{2}{c}{$\begin{array}{c}\text { Population Census } \\
\text { Year to April 2001 }\end{array}$} & & \multicolumn{2}{c}{$\begin{array}{c}\text { School Census } \\
\text { Year to January 2003 }\end{array}$} \\
\cline { 2 - 3 } \cline { 5 - 6 } Type of flow & Count & Per cent & & Count & Per cent \\
\hline Within district & 408,881 & 69.8 & & 544,117 & 75.2 \\
Between district & 177,218 & 30.2 & & 179,498 & 24.8 \\
All flows & $\mathbf{5 8 6 , 0 9 9}$ & $\mathbf{1 0 0}$ & & $\mathbf{7 2 3 , 6 1 5}$ & $\mathbf{1 0 0}$ \\
\hline
\end{tabular}

The School Census shows a steady decrease in propensity to migrate with age, reflecting the same pattern observed in the Population Census (Figure 3). The peak at age 11 in the School Census estimate of internal migration might reflect parental preference to move address at the same time as children are moving between primary and secondary schooling, but that preference is not shown in the Population Census. It may be a result of a lag in updating the home address on pupil records until a full check is made when the pupil enters a new school. For this reason the peak is not apparent for moves between districts, since normally such moves would involve a change of school at the time of the address move, avoiding a lag in recording the address move. When examined over time, the peak is mostly removed in later years of the School Census, suggesting that timely updating of records with address moves has improved. 


\section{Figure 3 Age at internal move, School Census and Population Census compared}

(a) Moves within districts in England by age of child (5-15)

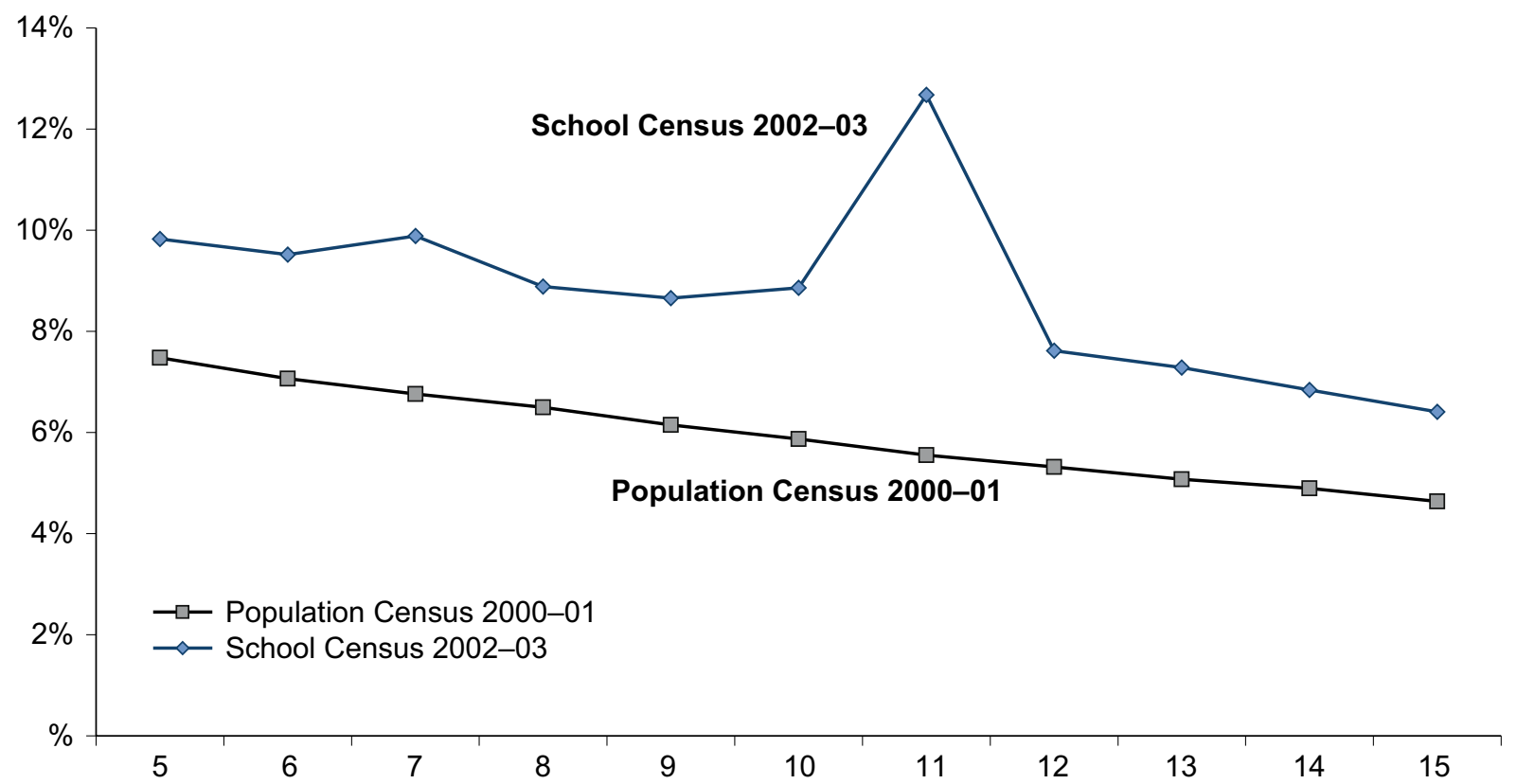

(b) Moves between districts in England by age of child (5-15)

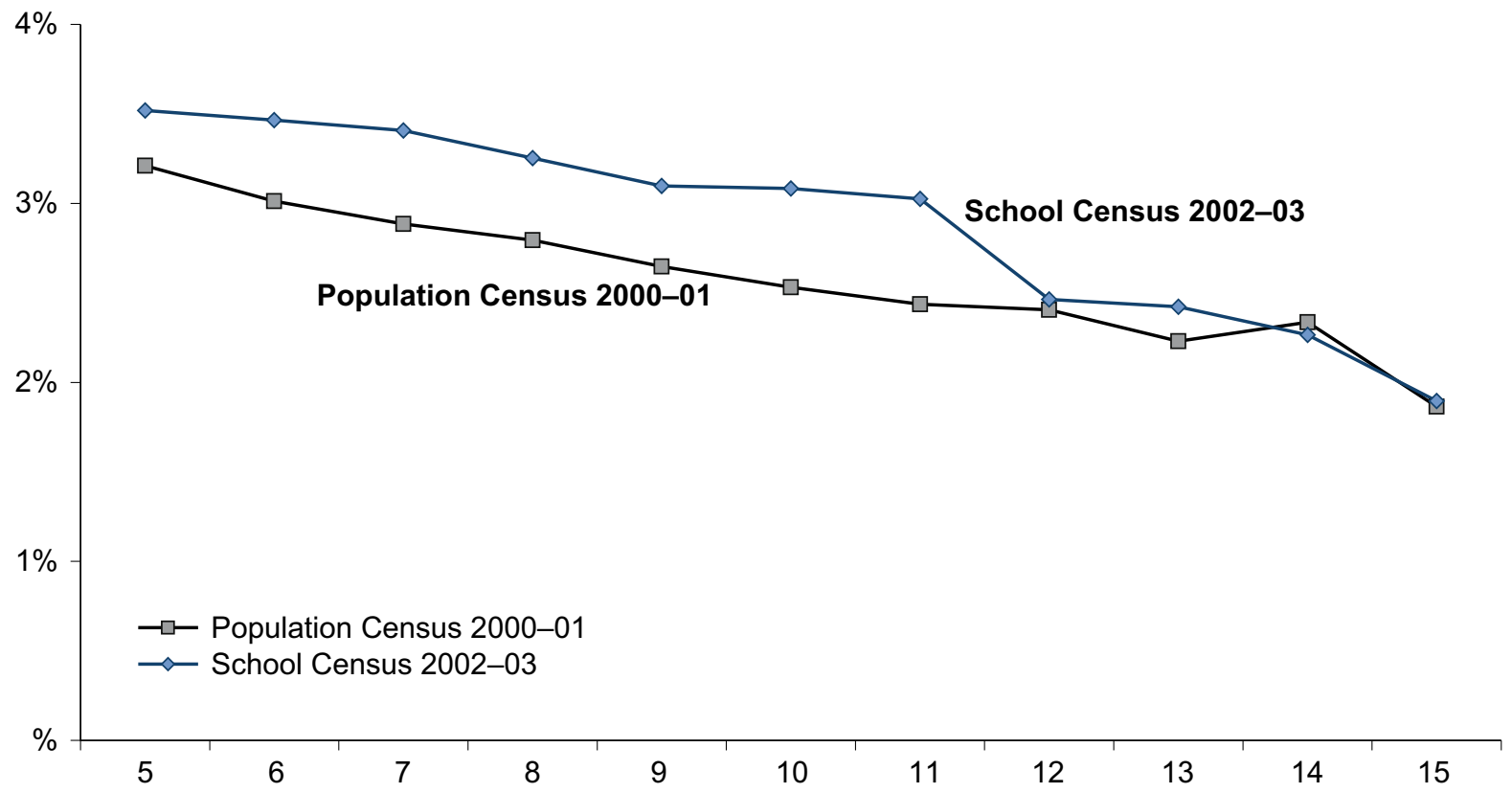

Note: Children who have moved in the year are shown as a percentage of all children on the dataset who might have moved

The Population Census also records the ethnicity of each child's move. The categories used in the Population Census are fewer than in the School Census, which in Figure $\mathbf{4}$ have been aggregated to the Census categories. The discrepancy between the two sources is greatest for categories which involve most ambiguity, including 'Other White' and 'Other Black'. There also seems to be a significant discrepancy for 'Black Caribbean', with a higher migration rate from the School Census, which may again be the varying interpretation and use of the category in different contexts 


\section{Figure 4 Ethnicity of pupils moving internally, School Census and} Population Census compared

(a) Moves within districts in England

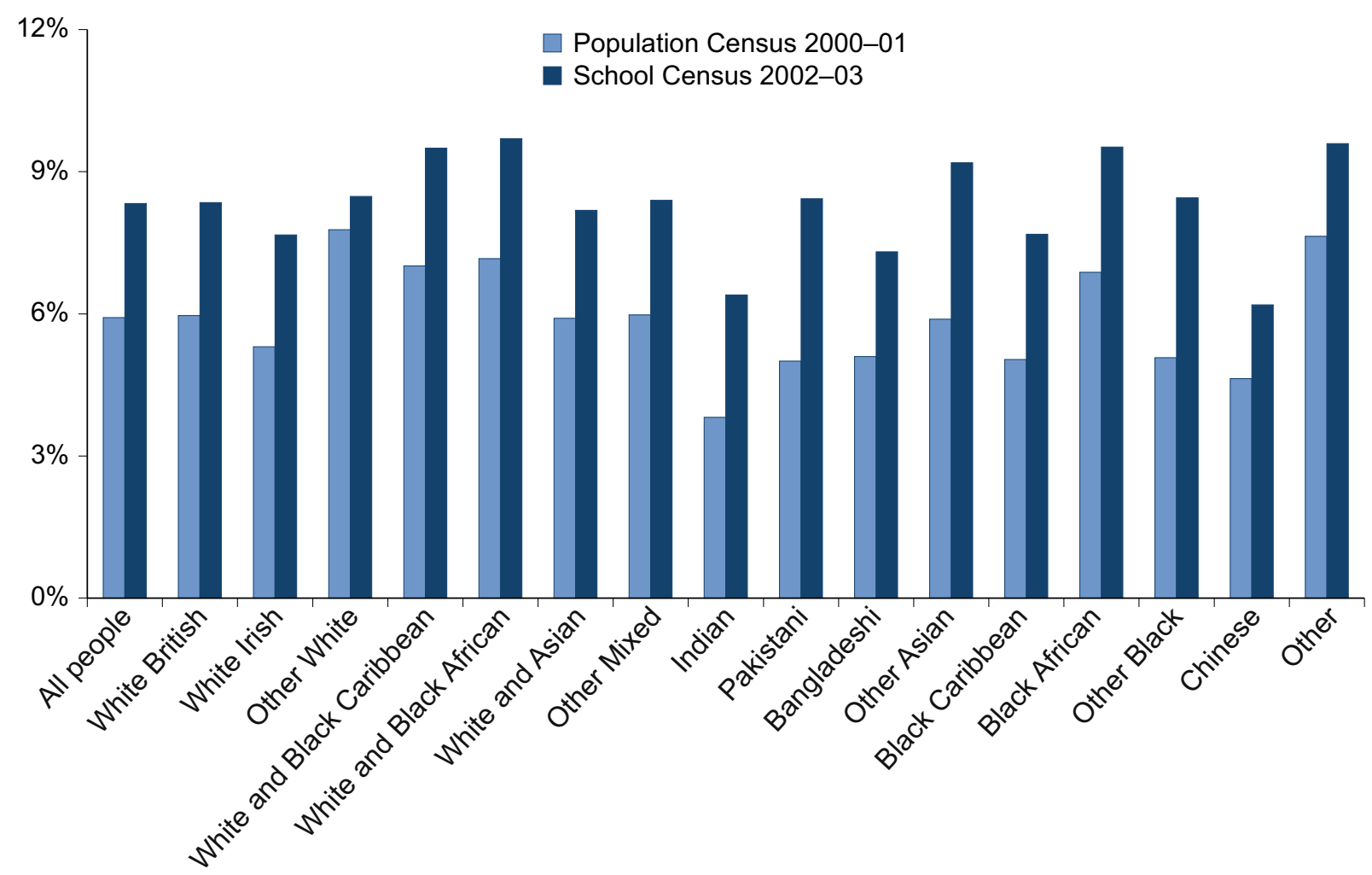

(b) Moves between districts in England

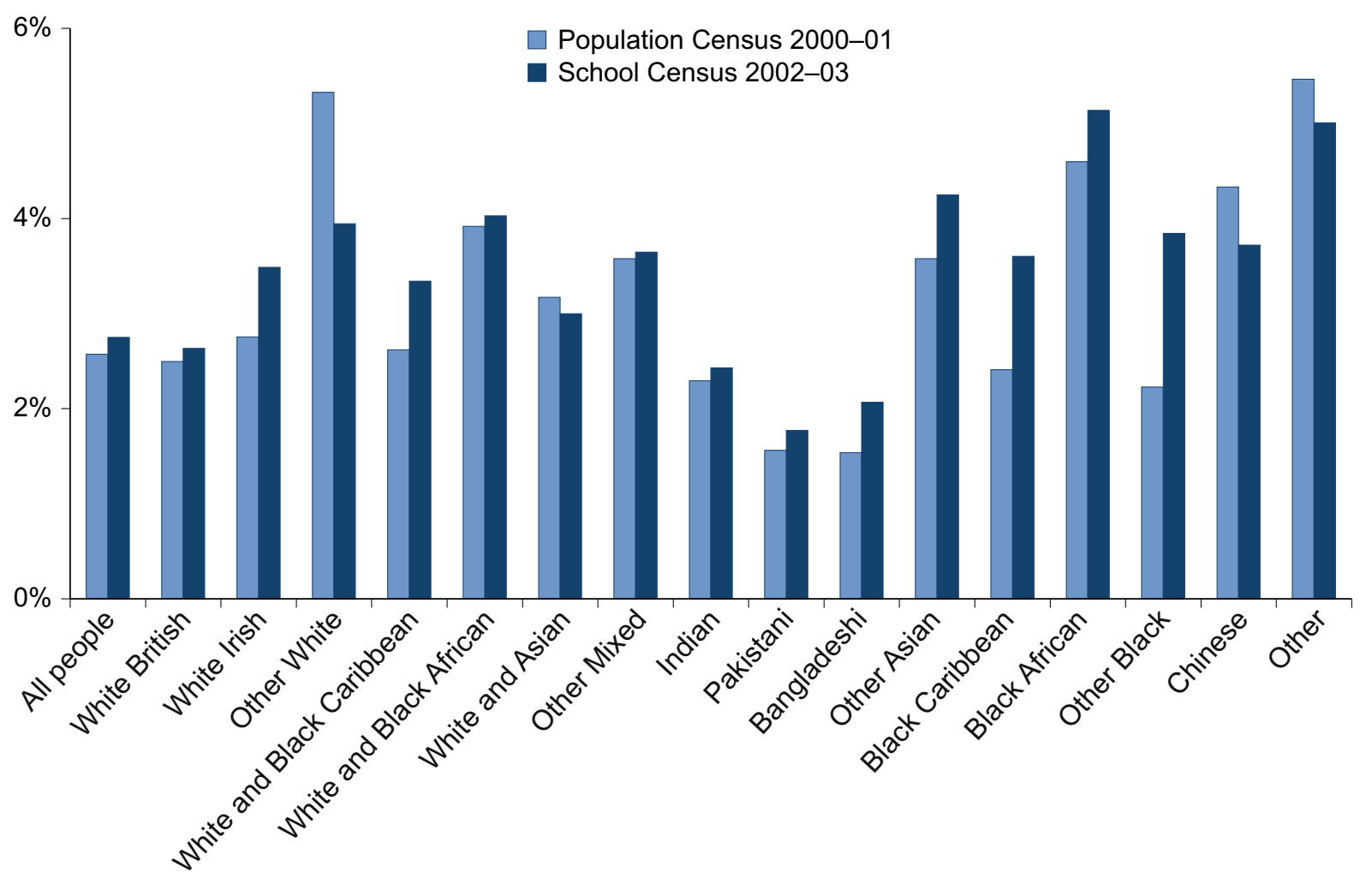


rather than a significant difference in measurement of migration itself. It is reassuring that the School Census identifies the same ethnic groups known from other analysis to have relatively low migration rates: Indian, Pakistani and Bangladeshi ${ }^{12}$.

\section{Other findings}

This article has focused on the methodology of measuring migration from School Census and comparison with accepted estimates of migration from other data sources. Initial analyses ${ }^{8}$ suggest $^{2}$ that the School Census will also provide new insights:

- Temporary immigrant pupils, those who are likely to be immigrants but then leave the state school system before age 15 , account for 13 per cent of all immigrant pupils; the majority appear in only one school year

- Pupils likely to be immigrants are three times more likely to move within England than other pupils

- Immigrant destinations are widening the geographical spread of ethnic diversity, away from traditional concentrations of non-White British ethnicities. This is so particularly, but not only, for Other White pupils

- Immigrant families moving to small towns and more rural areas have better economic circumstances than those moving to large towns and cities

The distribution of immigration within England changed in the middle of the last decade. The 186 thousand children who arrived as immigrants in the School Censuses of January 2003 to January 2007 (Table 4) were more likely to be living in urban areas (see Map 1). Overall, 64 per cent arrived in the last three of these five years, but this proportion was much higher outside the urban areas.

\section{Next steps}

The impact of social changes such as the recession of 2008-09, and of policy interventions such as area-based initiatives, are prime targets for research using the School Census. There is potential for wide analytical research use of the dataset by the government and academic sectors.

Key indicators for social policy available from the School Census include turnover of pupils in school, turnover of families in residential areas, numbers of welfare benefit claimants and their movement on and off benefit, families where English is not the first language, and the distance of moves made by migrants within England. Each of these indicators may be monitored for annual changes, for small areas, and for each recorded ethnic group. Each may be related to records of educational achievement held on the National Pupil Dataset of which the School Census is a part. In recognition of the value of the School Census to monitoring population change, ONS plans to link its records in a secure environment to a sample of birth records, to obtain a better understanding of the School Census data, assess the feasibility of data linkage and to assess the feasibility of providing statistical benefits through example analyses ${ }^{13}$. The statistical agencies of Scotland, Wales and Northern Ireland are also examining the equivalent pupil record systems within their countries, although they have each been running for fewer years than the School Census in England. There are not yet standard pupil reference numbers capable of identifying moves of individual pupils across national borders within the UK. 
Map 1 Percentage of immigrant pupils arriving between January 2002 and January 2007 as recorded in English School Census by local authority

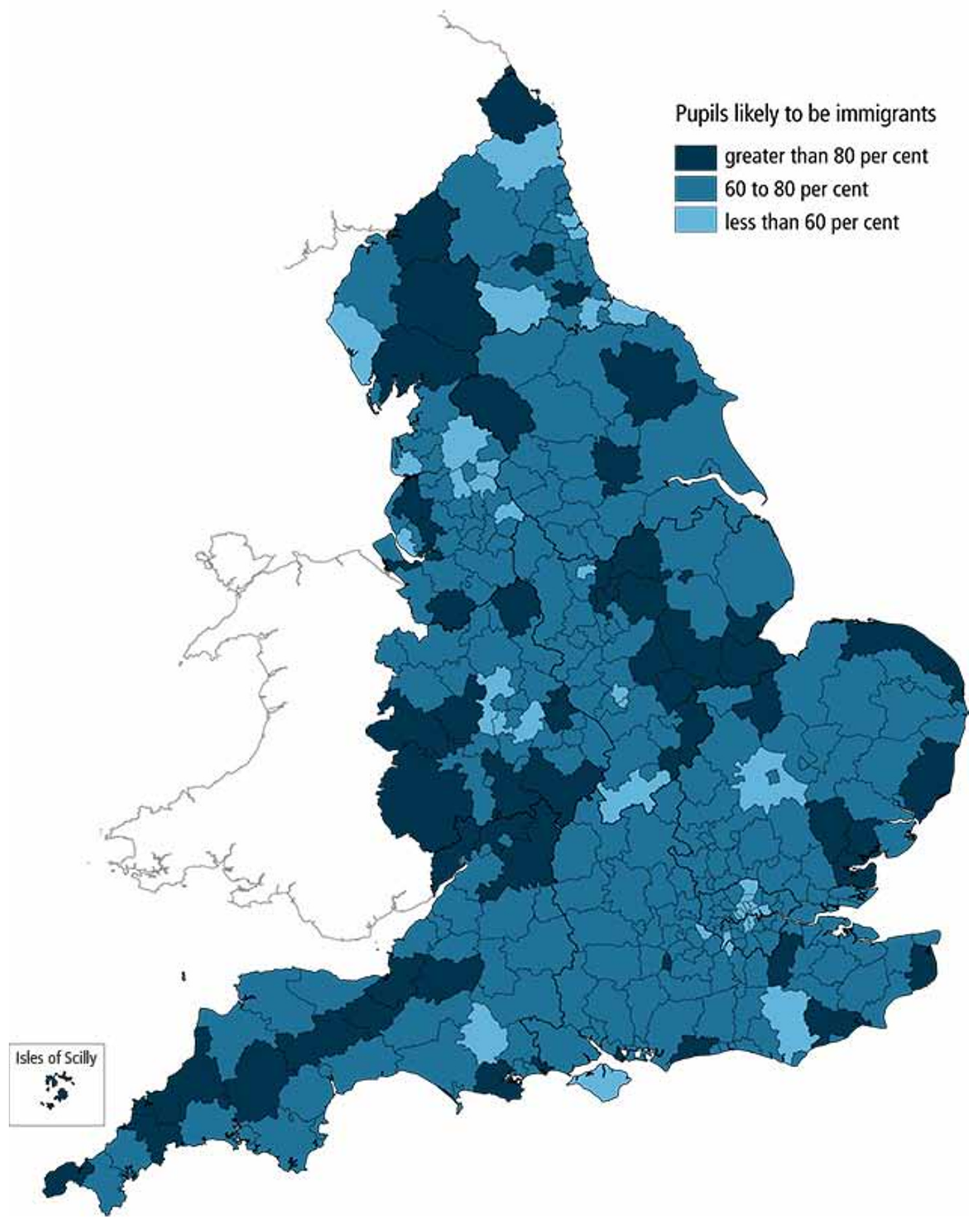


The wider use of the School Census for social policy research is currently held up by legislation which limits access to its records to research purposes associated with educational achievement, and to the ONS use for strictly demographic research. The current work was completed before the legislation was enforced. Government departments are discussing how to make the most of the dataset for social research within necessary safeguards and legislation for security of confidential information.

\section{Key findings}

The School Census, part of the National Pupil Database, tracks the residential moves of children aged 5-15 who are in and stay in the state school system in England:

- The quality of the postcode data is very high, with moves within England indicated by a change in postcode between years. The quality of internal child migration measures matches and possibly surpasses the Population Census and NHS patient records, while being more frequent and up-to-date than the former and providing more information than the latter

- Moves from overseas are indicated in this article by entry into England's state school system after age 5 by pupils with a first language other than English. Similarly, emigration is indicated by pupils who leave the school system before age 15

- These indicators identify pupils likely to be international migrants, but omit the substantial number whose first language is English as well as those who immigrated before school age, and include others who have moved from other parts of the UK and from outside the state school system. The indicators may be useful to estimate the local distribution of immigrants and emigrants, but not their absolute number

- The School Census powerfully complements existing sources of information on migration. It shows the changing distribution of migration to England and within England, with detail of ethnicity, language and an economic indicator.

\section{References}

1 Social Exclusion Unit (2000) National strategy for neighbourhood renewal: Report of Policy Action Team 18 - Better Information, Cabinet Office, Social Exclusion Unit, The Stationery Office, London.

2 Government encourages use of local statistics through its neighbourhood statistics databases. Available at: www.neighbourhood.statistics.gov.uk/dissemination/

3 Report of the Inter-Departmental Task Force on Migration Statistics, National Statistics, 15 December 2006. Available at: www.statistics.gov.uk/about/data/methodology/specific/ population/future/imps/updates/downloads/TaskForceReport151206.pdf

4 UK Statistics Authority (2009) Migration statistics: the way ahead? London: The UK Statistics Authority. House of Commons Treasury Committee (2008) Counting the Population, Eleventh Report of Session 2007-08, 23 May 2008, Report HC 183. Available at: www.publications.parliament.uk/pa/cm200708/cmselect/cmtreasy/183/183.pdf 
5 Scott, A. and Vickers, L. (2002) Internal migration by ethnic group: data sources, in Population projections by ethnic group, a feasibility study (ed. Haskey, J.) TSO London, pp 105-113 (Chapter 8).

6 See pp 61-68 in Simpson, S. (1998) Making local population statistics: a practitioner's guide, Local Authority Research and Intelligence Authority, Middlesborough.

7 Ewens, D. (2005) The National and London Pupil Datasets: An introductory briefing for researchers and research users. Greater London Authority, DMAG Briefing 2005/8.

8 Simpson, Jivraj and Marquis (in press) International and internal migration of ethnic minorities, measured from the National Pupil Dataset, published by the Department of Communities and Local Government, provides a fuller account of our processing, validation and analysis. See also related papers by Jivraj and Marquis. Available at: www.ccsr.ac.uk/publications/working/

9 Office for National Statistics (2004) Pupils and teachers: by type of school, 2002/03. Regional Trends, nr 38. Available at:

www.statistics.gov.uk/downloads/theme_compendia/Regional_Trends_38/rt38.pdf

10 Office for National Statistics (2007) Estimating Internal Migration: Customer Guidance Notes. Available at: www.statistics.gov.uk/statbase/EXPODATA\%5Ccommentary\%5CEstimatinginternalMigration.doc

11 Stillwell J, Duke-Williams O. 2007. 'Understanding the 2001 Census migration and commuting data: the effect of small cell adjustment and problems of comparison with 1991.' Journal of the Royal Statistical Society, Series A, Statistics in Society 170: 425-446.

12 Finney, N. and Simpson, L. (2008) 'Internal migration and ethnic groups: evidence for Britain from the 2001 Census', Population, Space and Place, 14(1): 63-83.

13 Office for National Statistics (2010) 'Feasibility linkage of Births records to School Census records'. Available at:

www.ons.gov.uk/about-statistics/methodology-and-quality/imps/updates- reports/currentupdates-reports/feasibility-linkage-of-births-records-to-school-census-records_march-2010.pdf 